Pathophysiology of Haemostasis and Thrombosis
Pathophysiol Haemost Thromb 2002;32:155-157

DOI: $10.1159 / 000070420$
Received: March 8, 2002

Accepted after revision: September 2, 2002

\title{
Effect of Low-Dose Aspirin on the International Normalized Ratio Variability in Patients with Mechanical Heart Valve Prostheses
}

\author{
Patricia Casais Susana S. Meschengieser Analia G. Sanchez Luceros \\ Emilse I. Bermejo Maria A. Lazzari
}

Hemostasis and Thrombosis Department, Institute of Hematological Research, National Academy of Medicine, Buenos Aires, Argentina

\section{Key Words}

International normalized ratio variability · Aspirin $\cdot$ Heart valve prostheses, mechanical $\cdot$ Bleeding risk

\begin{abstract}
An increased risk of bleeding is associated with a more intense oral anticoagulation, a greater international normalized ratio (INR) variability and the use of aspirin. We studied the INR variability of patients ( $n=121$ ) with modern heart valves who had been prospectively randomized to receive acenocoumarol at a targeted INR of 2.43.6 plus aspirin $100 \mathrm{mg} /$ day or acenocoumarol alone at the same dosage, to evaluate whether aspirin influences variability and thus the risk of bleeding. Variability was similar in patients with no events regardless of the use of aspirin. A statistically significantly higher variability was observed in patients with bleeding events independently of the use of aspirin. Nevertheless, the concomitant use of aspirin in patients with a high variability should be monitored closely and thoroughly.
\end{abstract}

Copyright $@ 2002$ S. Karger AG, Basel

\section{Introduction}

Mechanical heart valve replacement denotes a paradigm of a lifelong thromboembolic condition requiring adequate anticoagulation therapy to avoid disabling or fatal complications. For years, attempts have been made to achieve a high international normalized ratio (INR) in order to offer a greater protection from thromboembolism or valve thrombosis. The cost of such intense anticoagulation was an increase in major bleeding, which could also be disabling or fatal. The management of oral anticoagulation therapy in prosthetic heart valves has changed in recent years to adjust protection and risks to new valves made of less thrombogenic materials. Current recommendations propose that the anticoagulation intensity should be lowered and a low dose of aspirin should be added in patients at higher risk of embolism [1].

An increased risk of bleeding is associated with both a more intense oral anticoagulation (i.e. a higher INR) and the use of aspirin [2-6]. It has also been demonstrated that a greater INR variability is an independent risk factor for major bleeding [7-9] in patients who are chronically anticoagulated.

A recent meta-analysis [10] of anticoagulation in mechanical heart valve prostheses showed that adding aspi-

Patricia Casais, MD

Pacheco de Melo 3081

1425 Buenos Aires (Argentina)

Tel./Fax +541148050712, E-Mail casais@hematologia.anm.edu.ar
Fax +41613061234 E-Mail karger@karger.ch www.karger.com
Accessible online at: www. karger.com/pht 
Table 1. Patients characteristics

\begin{tabular}{lll}
\hline & $\begin{array}{l}\text { Aspirin }+ \\
\text { acenocoumarol } \\
(\mathrm{n}=57)\end{array}$ & $\begin{array}{l}\text { Acenocoumarol } \\
\text { alone } \\
(\mathrm{n}=64)\end{array}$ \\
\hline $\begin{array}{ll}\text { Median age (range), years } \\
\text { Sex (female), \% }\end{array}$ & $56.85(14-81)$ & $57.55(17-84)$ \\
Valve position, \% & 43 & 52 \\
$\quad$ Mitral & 26 & 20 \\
$\quad$ Aortic & 67 & 75 \\
$\quad$ Mitroaortic & 7 & 5 \\
Total follow-up, years & 95.4 & 89.2 \\
Median INR during follow-up & $2.95 \pm 1.17$ & $2.95 \pm 1.31$ \\
Time, \% & & \\
$\quad$ Within therapeutic range & 54.01 & 54.30 \\
$\quad$ Over therapeutic range & 16.91 & 16.28 \\
$\quad$ Below therapeutic range & 29.08 & 29.42 \\
INR variability & & \\
$\quad$ No events & 0.67 & 0.57 \\
$\quad$ Bleeding & 0.85 & 1.52 \\
\hline
\end{tabular}

rin to warfarin decreases the risk of embolism and death, though at the expense of an increase in the risk of major hemorrhage. Nevertheless, in our previous study [6], which accounted for almost half of the patients included in the meta-analysis, patients with mechanical heart valve prostheses anticoagulated at a lower INR plus aspirin did not show higher bleeding rates than patients with higher intended INR without aspirin.

Our objective was to prospectively study the INR variability in patients with modern heart valves targeted to the same INR but with and without low-dose aspirin to evaluate whether aspirin influences the variability and thus the risk of bleeding.

\section{Patients, Material and Methods}

Between 1995 and 1999 patients within 6 months of surgery were randomized to receive acenocoumarol at a targeted INR of 2.4-3.6 plus aspirin $100 \mathrm{mg} /$ day or acenocoumarol alone at the same dosage. Every INR was entered into the database. To calculate the INR variability we used the formula by Fihn et al. [7] with a modification already reported [8] in order to use the INR measurement instead of the prothrombin time ratio since this is the usual way in which anticoagulation therapy is monitored:

$$
\sigma=\sqrt{\frac{1}{(n-1)} \sum_{i=2}^{n} \frac{\left(\mathrm{INR}_{\mathrm{i}}-\mathrm{INR}_{\mathrm{i}-1}\right)^{2}}{\pi_{\mathrm{i}}}}
$$

In this formula, $\sigma$ represents the calculated deviation or variability in the INR over time, $\mathrm{n}$ is the number of laboratory measurements and $\pi$ is the time between tests expressed in weeks. Total follow-up and time within the therapeutic range were assessed using Rosendaal's half method [11].

Values are expressed as means. Results were compared using the $\chi^{2}$ test, Fisher's exact test or F test as appropriate. The statistical significance was set at $\mathrm{p}$ values $<0.05$. Calculations were performed with the Statistical Package for Social Sciences (SPSS Inc., Chicago Ill., USA, version 9.0 for Windows) software and the Epi Info, 6.04 version from the Center for Disease Control and Prevention (CDC), Epidemiology Program Office, USA.

Minor and major bleeding episodes were recorded. A major bleeding was defined as in a previous report [2].

\section{Results}

Patients $(n=121)$ with tilting disc or bileaflet prosthetic heart valves were included within 6 months of surgery. Fifty-seven patients were randomized to acenocoumarol plus aspirin while 64 patients received acenocoumarol alone. Patient characteristics of both groups were comparable as well as total follow-up, time within the therapeutic range and median INR during follow-up (table 1). More bleeding episodes were observed in patients with aspirin ( 5 major and 6 minor events vs. 3 major and 3 minor without aspirin), even though this difference did not reach statistical significance. There were no deaths.

We determined the INR variability in each patient. The variability was similar in patients with no events regardless of the use of aspirin (0.67 and 0.57 , with and without aspirin, respectively). In patients with bleeding complications (regardless of whether they were on aspirin) a statistically significantly higher variability was observed compared to the variability in patients with no events with or without aspirin ( $p=0.02)$. But the concomitant use of aspirin $100 \mathrm{mg} /$ day did not increase the variability in patients with hemorrhage ( 0.85 and 1.52 , with or without aspirin, respectively).

\section{Discussion}

INR variability is an independent risk factor for hemorrhage [7-9, 12] and combination therapy with oral anticoagulants and aspirin has been associated with an increase in bleeding complications in cardiovascular diseases $[1,10]$. Our objectives were to study the INR variability in patients with modern heart valves randomized to the same oral anticoagulation intensity but with or without low-dose aspirin in order to evaluate the influence of the antiplatelet agent in the variability and in the bleeding complications. 
The antithrombotic potential of aspirin is mainly achieved by the inactivation of platelet COX-1 but enhancement of fibrinolysis and suppression of plasma coagulation have also been postulated [5]. The antithrombotic effect of aspirin is not dose-related [5], and neither is the bleeding effect $[13,14]$. In spite of this, the meta-analysis by Massel and Little [10] showed that the risk of major bleeding was increased in patients with mechanical heart valves receiving warfarin plus aspirin, but decreased when lower doses of aspirin were used.

Even though we studied a small population which had few hemorrhages, our findings agree with previous reports $[7-9,12]$ regarding the value of INR fluctuation as a bleeding risk indicator since a greater variability was observed in patients with hemorrhage. However, lowdose aspirin did not increase the variability either in the arm randomized to aspirin or in the patients with bleed- ing complications. Our observations suggest that the potential increased risk of bleeding due to aspirin is not related to its interaction with oral anticoagulant drugs, at least when low doses are used. It is possible that with higher aspirin doses there may be pharmacokinetic interactions with anti-vitamin $\mathrm{K}$ agents [15].

Nevertheless, the potential increased risk of bleeding as a result of aspirin seems to be related to individual characteristics and therefore the concomitant use of aspirin in patients with a high variability should be monitored closely and thoroughly.

\section{Acknowledgment}

This work was supported by a grant from the Rene Baron Foundation.

\section{References}

1 Stein PD, Alpert JS, Bussey HI, Dalen JE, Turpie AGG: Antithrombotic therapy in patients with mechanical and biological prosthetic heart valves. Chest 2001;119:220S-227S.

2 Casais P, Sánchez Luceros A, Meschengieser S, Fondevila C, Santarelli MT, Lazzari MA: Bleeding risk factors in chronic oral anticoagulation with acenocoumarol. Am J Hematol 2000;63:192-196.

3 Palareti G, Leali N, Cocheri S, Poggi M, Manotti C, D'Angelo A, Pengo V, Erba N, Moia M, Ciavarella N, Devoto G, Berettini M, Musolesi S: Bleeding complications of oral anticoagulant treatment: An inception-cohort, prospective collaborative study (ISCOAT). Lancet 1996;348:423-428.

4 Patrono C, Coller B, Alen JE, Fitzgerald GA, Fuster V, Gent M, Hirsch J, Roth G: Plateletactive drugs. The relationship among dose, effectiveness, and side effects. Chest 2001;119: 39S-63S.
5 Saour JN, Sieck JO, Mamo LA, Gallus AS: Trial of different intensities of anticoagulation in patients with prosthetic heart valves. N Engl J Med 1990;322:428-432.

6 Meschengieser SS, Fondevila CG, Santarelli MT, Lazzari MA: Low intensity oral anticoagulation plus low-dose aspirin versus high-intensity oral anticoagulation alone: A randomized trial in patients with mechanical prosthetic heart valves. J Thorac Cardiovasc Surg 1997; 113:910-916.

7 Fihn SD, Callahan CM, Martin DC, Mc Donell MB, Henikoff JG, White RH: The risk for and severity of bleeding complications in elderly patients treated with warfarin. Ann Intern Med 1996;124:970-979.

8 Casais P, Sánchez Luceros A, Meschengieser SS, Bermejo E, Lazzari MA: INR variability in anticoagulation with acenocoumarol: Is it useful for identifying patients at risk of bleeding and thrombosis? Haematologica 1999;84:753754.

9 Fihn SD, Mc Donell M, Martin D, Henikoff J, Vermes D, Kent D, White RH: Risk factors for complications of chronic anticoagulation. Ann Intern Med 1993;118:511-520.
10 Massel D, Little SH: Risks and benefits of adding anti-platelet therapy to warfarin among patients with prosthetic heart valves: A metaanalysis. J Am Coll Cardiol 2001;37:569-578.

11 Rosendaal FR, Cannegetier SC, van der Meer FJ, Briet E: A method to determine the optimal intensity oral anticoagulant therapy. Thromb Haemost 1993;69:236-239.

12 Kent DL, Vermes D, Mc Donell M, Henikoff J, Fihn SD: A model for planning optimal followup for out-patients on warfarin anticoagulation. Med Decis Making 1992;12:132-141.

13 de Abajo FJ, García Rodríguez LA: Risk of upper gastrointestinal bleeding and perforation associated with low-dose aspirin as plain and enteric-coated formulations. BMC Clin Pharmacol 2001;1:1.

14 Derry S, Loke YK: Risk of gastrointestinal haemorrhage with long term use of aspirin: Meta-analysis. BMJ 2000;321:1183-1187.

15 Fiske WD, Connell JM, Benedek ICH: Lack of pharmacokinetic interaction between aspirin and warfarin. Am J Ther 1995;2:407-413. 